\title{
Global climate forcing of aerosols embodied in international trade
}

\author{
Jintai Lin ${ }^{1 \star \dagger}$, Dan Tong ${ }^{2 \dagger}$, Steven Davis ${ }^{3}$, Ruijing Ni ${ }^{1}$, Xiaoxiao Tan ${ }^{14}$, Da Pan $^{5}$, Hongyan Zhao ${ }^{2}$, \\ Zifeng L Lu$^{6}$, David Streets ${ }^{6}$, Tong Feng ${ }^{2}$, Qiang Zhang ${ }^{2 \star}$, Yingying Yan ${ }^{1}$, Yongyun Hu ${ }^{1}$, Jing Li ${ }^{1}$, Zhu Liu ${ }^{7}$, \\ Xujia Jiang ${ }^{2}$, Guannan Geng ${ }^{2}$, Kebin $\mathrm{He}^{8,9}$, Yi Huang ${ }^{4 \star}$ and Dabo Guan ${ }^{10}$
}

\begin{abstract}
International trade separates regions consuming goods and services from regions where goods and related aerosol pollution are produced. Yet the role of trade in aerosol climate forcing attributed to different regions has never been quantified. Here, we contrast the direct radiative forcing of aerosols related to regions' consumption of goods and services against the forcing due to emissions produced in each region. Aerosols assessed include black carbon, primary organic aerosol, and secondary inorganic aerosols, including sulfate, nitrate and ammonium. We find that global aerosol radiative forcing due to emissions produced in East Asia is much stronger than the forcing related to goods and services ultimately consumed in that region because of its large net export of emissions-intensive goods. The opposite is true for net importers such as Western Europe and North America: global radiative forcing related to consumption is much greater than the forcing due to emissions produced in these regions. Overall, trade is associated with a shift of radiative forcing from net importing to net exporting regions. Compared to greenhouse gases such as carbon dioxide, the short atmospheric lifetimes of aerosols cause large localized differences between consumption- and production-related radiative forcing. International efforts to reduce emissions in the exporting countries will help alleviate trade-related climate and health impacts of aerosols while lowering global emissions.
\end{abstract}

A nthropogenic aerosols influence the radiative balance of the climate system and constitute an important radiative forcing that drives global climate change $e^{1-5}$. Furthermore, the spatial pattern of aerosol forcing strongly affects regional climate $^{6-12}$-for example, Indian aerosols affect the summer monsoon precipitation ${ }^{8,12}$, and Asian aerosols affect the Pacific storm track ${ }^{10}$. Because aerosols stay in the atmosphere only for a few days, their effect on radiative forcing is most powerful around the regions where they or their precursor gases (from which these aerosols are formed) are emitted, with the potential for additional forcing due to aerosols transported to more distant areas by weather systems ${ }^{5-7,9,10}$. Industrial processes and fossil fuel burning lead to emissions of aerosols and precursors as a by-product, such that the emissions may be attributed to production of specific goods and services. In turn, international trade has increasingly enabled these production activities and their related aerosol emissions to occur far from where the goods and services are ultimately consumed. Accompanying the relocation of emissions is a change in the amount of emissions associated with a given product, as a result of regional differences in energy structure, energy efficiency, and emission control levels ${ }^{13,14}$. Although the important role of international trade in redistributing carbon and pollutant emissions $^{15-22}$ and altering regional air quality ${ }^{13,23}$ has been shown previously, the effects on climate forcing due to aerosols has never been assessed. Yet the potential implications for regional climate impacts are substantial, especially since aerosols are short-lived and exert strong spatially inhomogeneous forcing.

Here, we evaluate the role of trade in attributing top-of-theatmosphere direct aerosol radiative forcing (RF) as of 2007 , which is the most recent year for which all necessary data are available. As modelled, direct RF accounts for both scattering and absorption of solar radiation in the atmosphere, that is, through aerosolradiation interactions ${ }^{1}$. We quantify global direct $\mathrm{RF}$ related to emissions produced in, as well as goods and services consumed in, each of 11 world regions: East Asia (China, Mongolia, and North Korea), Economies in Transition (Eastern Europe and Former Soviet Union), North America (the United States and Canada), Western Europe, Middle East and North Africa, Southeast Asia and Pacific, Pacific OECD (Japan, South Korea, Australia, and New Zealand), Latin America and Caribbean, South Asia, Sub-Saharan Africa, and Rest of the World (Supplementary Fig. 1).

\section{Deriving emissions and radiative forcing}

We estimate global emissions of aerosols and precursors related to goods and services consumed in each region (consumption-based emissions, $E_{c}$ ) using a multiregional input-output model based on trade data for 129 countries/regions and 57 industry sectors ${ }^{24}$ and a newly built country- and sector-specific emission inventory

\footnotetext{
${ }^{1}$ Laboratory for Climate and Ocean-Atmosphere Studies, Department of Atmospheric and Oceanic Sciences, School of Physics, Peking University, Beijing 100871, China. ${ }^{2}$ Ministry of Education Key Laboratory for Earth System Modeling, Center for Earth System Science, Tsinghua University, Beijing 100084, China. ${ }^{3}$ Department of Earth System Science, University of California, Irvine, California 92697, USA. ${ }^{4}$ Department of Atmospheric \& Oceanic Sciences, McGill University, Montreal, Quebec H3A OB9, Canada. ${ }^{5}$ Department of Civil and Environmental Engineering, Princeton University, Princeton, New Jersey 08544, USA. ${ }^{6}$ Energy Systems Division, Argonne National Laboratory, Argonne, Illinois 60439, USA. ${ }^{7}$ Resnick Sustainability Institute, California Institute of Technology, Pasadena, California 91125, USA. ${ }^{8}$ State Key Joint Laboratory of Environmental Simulation and Pollution Control, School of Environment, Tsinghua University, Beijing 100084, China. ${ }^{9}$ Collaborative Innovation Center for Regional Environmental Quality, Beijing 100084, China. ${ }^{10}$ School of International Development, University of East Anglia, Norwich NR4 7TJ, UK. ${ }^{\dagger}$ These authors contributed equally to this work. *e-mail: linjt@pku.edu.cn; qiangzhang@tsinghua.edu.cn; yi.huang@mcgill.ca
} 

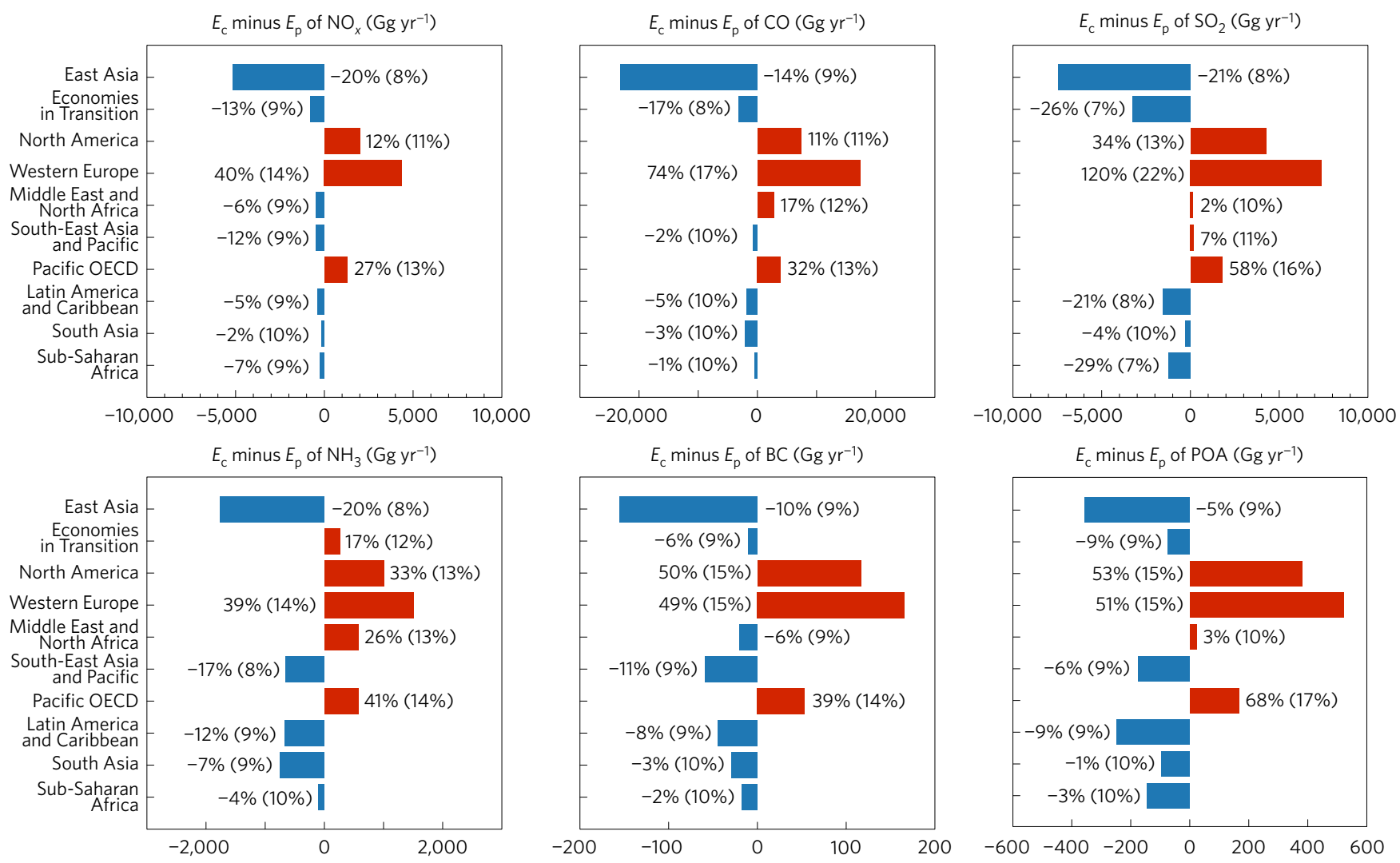

Figure 1 | Net aerosol emissions embodied in trade. $E_{\mathrm{c}}-E_{\mathrm{p}}$ for ten regions and six aerosol-related species; the values for Rest of the World (including Greenland and the Antarctic) are negligible and omitted here. For a given region, the percentage value indicates the relative change from $E_{\mathrm{p}}$ to $E_{\mathrm{c}}$, and the value in the parenthesis is the associated error $(2 \sigma)$.

of emissions produced within each region (production-based emissions, $E_{\mathrm{p}}$ ) (Supplementary Methods 1 and 2). Emitted species include nitrogen oxides $\left(\mathrm{NO}_{x}\right)$, sulfur dioxide $\left(\mathrm{SO}_{2}\right)$, ammonia $\left(\mathrm{NH}_{3}\right)$, carbon monoxide $(\mathrm{CO})$, black carbon $(\mathrm{BC})$, and primary organic aerosol (POA). Although it is not an aerosol precursor, $\mathrm{CO}$ is included due to its influence on the atmospheric oxidative capacity that affects the formation of secondary aerosols.

We then calculate production-based direct radiative forcing $\left(\mathrm{RF}_{\mathrm{p}}\right)$ and consumption-based direct radiative forcing $\left(\mathrm{RF}_{\mathrm{c}}\right)$ for each of the 11 regions (Supplementary Methods 3-5). We use the chemical transport model GEOS-Chem to simulate the atmospheric evolution of emitted $\mathrm{BC}$ and POA and secondary inorganic aerosols (SIOA, including sulfate, nitrate and ammonium) that are formed in the atmosphere from the emitted $\mathrm{NO}_{x}, \mathrm{SO}_{2}$ and $\mathrm{NH}_{3}$ gases. Subsequently, we employ the radiative transfer model RRTMG to calculate the RF of BC, POA and SIOA. Cumulative global RF from included aerosols is about $0.32 \mathrm{~W} \mathrm{~m}^{-2}$ for $\mathrm{BC},-0.10 \mathrm{~W} \mathrm{~m}^{-2}$ for POA, and $-0.48 \mathrm{~W} \mathrm{~m}^{-2}$ for SIOA, which are consistent with the mean values reported in the Intergovernmental Panel on Climate Change (IPCC) Fifth Assessment Report $(\mathrm{AR} 5)^{1}(0.40,-0.09$ and $-0.51 \mathrm{~W} \mathrm{~m}^{-2}$ for aerosol-radiation interactions for $\mathrm{BC}, \mathrm{POA}$ and SIOA, respectively) ${ }^{1}$. In magnitude, the $\mathrm{RF}$ of SIOA and $\mathrm{BC}$ is $18-26 \%$ of the RF of carbon dioxide $\left(\mathrm{CO}_{2}, 1.82 \mathrm{~W} \mathrm{~m}^{-2}\right)$, and is comparable to the $\mathrm{RF}$ of methane $\left(0.48 \mathrm{~W} \mathrm{~m}^{-2}\right)$ and ozone $\left(0.35 \mathrm{~W} \mathrm{~m}^{-2}\right)$. Hereafter, we sum the negative RF of SIOA and POA.

\section{Roles of trade in redistributing emissions and direct RF}

Figure 1 shows regional differences in consumption- and production-based aerosol emissions (that is, $E_{\mathrm{c}}-E_{\mathrm{p}}$ ), or the net emissions embodied in trade (emissions embodied in imports less emissions embodied in exports), for six aerosol and precursor species. Globally, 20\% of $\mathrm{NO}_{x}$ emissions, $13 \%$ of CO, $26 \%$ of
$\mathrm{SO}_{2}, 16 \%$ of $\mathrm{NH}_{3}, 11 \%$ of $\mathrm{BC}$ and $6 \%$ of $\mathrm{POA}$ in 2007 are related to production of goods and services that are consumed in a different region. Net exports are consistently largest for East Asia, representing about $20 \%$ of $\mathrm{NO}_{x}, \mathrm{SO}_{2}$ and $\mathrm{NH}_{3}(5,138,7,437$ and $1,765 \mathrm{Gg}$, respectively), $10 \%$ of $\mathrm{BC}(155 \mathrm{Gg})$, and $5 \%$ of POA $(357 \mathrm{Gg})$ produced in the region, broadly consistent with previous estimates $^{13,21}$. Except for POA, these percentage differences exceed their associated uncertainties. For comparison, the emissions exported on net from East Asia represent 47\%, 121\%, 46\%, $46 \%$ and $35 \%$ of the $\mathrm{NO}_{x}, \mathrm{SO}_{2}, \mathrm{NH}_{3}, \mathrm{BC}$ and $\mathrm{POA}$ produced in Western Europe, respectively. Net imports to Western Europe and North America embody the largest quantities of emissions, with consumption-based emissions, $E_{c}$, that exceed those regions' production-based emissions, $E_{\mathrm{p}}$, by $39-120 \%$ in Western Europe and by $11-53 \%$ in North America (depending on the species). Overall, $E_{\mathrm{c}}$ of the developed (developing) counties are larger (lower) than their $E_{\mathrm{p}}$, in line with previous emission studies ${ }^{15,20,22}$.

Attributing emissions to the region where products are ultimately consumed means considerable re-attribution of RF at the regional scale. Supplementary Figs 4 and 5 show the horizontal distributions of $\mathrm{RF}_{\mathrm{p}}, \mathrm{RF}_{\mathrm{c}}$ and their differences for SIOA+POA and $\mathrm{BC}$, respectively. The $\mathrm{RF}_{\mathrm{p}}$ maps highlight the effect of atmospheric transport in transferring aerosols from the regions of emissions to downwind places, for example, from East Asia to most regions in the Northern Hemisphere. The $\mathrm{RF}_{\mathrm{c}}$ maps emphasize attribution of aerosol forcing related to regions' consumption by accounting for trade, for example, from most regions to East Asia. Overall, traderelated relocation of production means that consumption in any region leads to aerosol forcing all over the world, to an extent much beyond the effect of atmospheric transport alone. Supplementary Fig. 6 further shows that although the positive forcing of BC largely compensates for the negative forcing of SIOA+POA on a global 


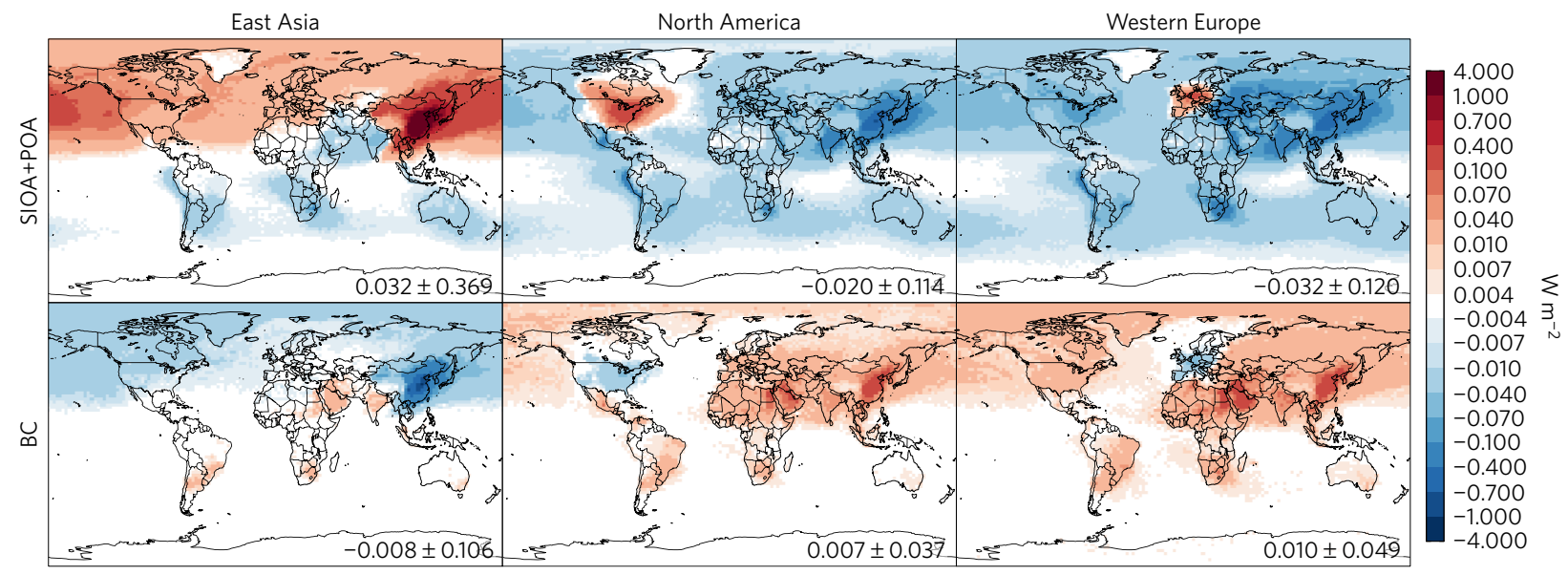

Figure 2 | Global differences between consumption- and production-based radiative forcing $\left(R_{c}-R F_{p}\right)$. The three columns refer to $R F$ contributed by East Asia, North America and Western Europe, respectively.

mean basis, regionally the locations of $\mathrm{BC}$ forcing do not always correlate to the locations of SIOA+POA forcing, leading to a clear spatial pattern of positive and negative forcing that affects the regional climate.

Figure 2 highlights the spatial distribution of the difference between $\mathrm{RF}_{\mathrm{c}}$ and $\mathrm{RF}_{\mathrm{p}}$ contributed by East Asia (first column), North America (second column) and Western Europe (third column). Given the cooling effect of SIOA+POA, red colours in panels of the first row indicate areas where consumption-based forcing is less negative than production-based forcing. For BC (second row) whose radiative forcing is positive, similar patterns are visible but with an opposite sign. For each panel, the global mean value is smaller than the standard deviation by a factor of $4-13$, highlighting the drastic spatial inhomogeneity of the radiative forcing embodied in trade.

For East Asia (Fig. 2, first column), the magnitude of $\mathrm{RF}_{\mathrm{c}}$ is larger than $\mathrm{RF}_{\mathrm{p}}$ over the Southern Hemisphere, the Middle East and India, with stronger negative forcing of SIOA+POA (by up to $-0.07 \mathrm{~W} \mathrm{~m}^{-2}$ ) and stronger positive forcing of $\mathrm{BC}$ (by up to $0.04 \mathrm{~W} \mathrm{~m}^{-2}$ ). This means that aerosol forcing due to emissions released in these regions associated with consumption in East Asia is stronger than the effect of atmospherically transported aerosols due to emissions released in East Asia. Over most of the Northern Hemisphere, the $\mathrm{RF}_{\mathrm{c}}$ contributed by East Asia is weaker in magnitude than its $\mathrm{RF}_{\mathrm{p}}$. This is because the productionrelated aerosol concentrations greatly exceed concentrations of consumption-related aerosols over East Asia, and the atmospheric transport of excess production-related aerosols more than offsets the effect of trade-associated emission relocation.

For North America (Fig. 2, second column), the magnitude of $\mathrm{RF}_{\mathrm{c}}$ exceeds its $\mathrm{RF}_{\mathrm{p}}$ across most of the world. The difference is greatest over eastern China, with a peak value of $-1.0 \mathrm{~W} \mathrm{~m}^{-2}$ for $\mathrm{SIOA}+\mathrm{POA}$ and $0.4 \mathrm{~W} \mathrm{~m}^{-2}$ for $\mathrm{BC}$. The negative values for SIOA+POA over western North America suggest that both eastern and western North America outsources production to East Asia, and the consequently enhanced atmospheric transport of East Asian aerosols more than offsets the effect of outsourcingcaused reduction in western North American emissions ${ }^{13}$. This represents net transfer of aerosol RF from eastern to western North America. For Western Europe (Fig. 2, third column), the magnitude of $\mathrm{RF}_{\mathrm{c}}$ is stronger than its $\mathrm{RF}_{\mathrm{p}}$ over most of the globe, with the largest differences over eastern China and the Middle East (by up to $-0.7 \mathrm{~W} \mathrm{~m}^{-2}$ for SIOA+POA and $0.4 \mathrm{~W} \mathrm{~m}^{-2}$ for BC). Overall, we find that the combination of trade and atmospheric transport means effective globalization of aerosol RF associated with a given region's consumption.
Figure 3a,b summarizes the global average $R_{c}$ and $R F_{p}$ contributed by individual regions. The magnitude of both $\mathrm{RF}_{\mathrm{c}}$ and $\mathrm{RF}_{\mathrm{p}}$ contributed by East Asia is the largest, followed by South Asia and Sub-Saharan Africa. Exports of these regions produce stronger aerosol forcing than their imports, and thus their $\mathrm{RF}_{c}$ are weaker in magnitude than $\mathrm{RF}_{\mathrm{p}}$, although the $\mathrm{RF}$ differences are often within the associated uncertainties for South Asia and Sub-Saharan Africa. In particular, the $\mathrm{RF}_{\mathrm{c}}$ contributed by East Asia is $-0.14 \mathrm{~W} \mathrm{~m}^{-2}$ for SIOA+POA and $0.077 \mathrm{~W} \mathrm{~m}^{-2}$ for $\mathrm{BC}$, weaker than its $\mathrm{RF}_{\mathrm{p}}$ at -0.17 and $0.085 \mathrm{~W} \mathrm{~m}^{-2}$, respectively. The $\mathrm{RF}_{\mathrm{c}}$ versus $\mathrm{RF}_{\mathrm{p}}$ differences, $-0.03 \mathrm{~W} \mathrm{~m}^{-2}$ for SIOA+POA and $0.008 \mathrm{~W} \mathrm{~m}^{-2}$ for $\mathrm{BC}$, are comparable to the absolute magnitude of $\mathrm{RF}_{\mathrm{p}}$ contributed by Western Europe (for SIOA+POA) and North America (within 25\% for both SIOA+POA and BC).

Figure 3a,b also shows that Western Europe, North America and Pacific OECD are net importers of goods, thus the radiative forcing related to their consumption, $\mathrm{RF}_{c}$, is stronger than the forcing related to their produced emissions, $\mathrm{RF}_{\mathrm{p}}$, by $51-105 \%$ for $\mathrm{SIOA}+\mathrm{POA}$ and by $69-94 \%$ for BC. A similar result is shown in Supplementary Fig. 7 for the net forcing of SIOA+POA+BC, although the cooling effect of SIOA+POA is largely offset by the warming effect of $\mathrm{BC}$ on a global mean basis.

For RF contributed by any given region, Fig. 3c,d depicts the percentage of forcing imposed upon the region's own territory; a metric to evaluate how much trade and atmospheric transport redistribute the aerosol RF. The territorial (domestic) percentage for $\mathrm{RF}_{\mathrm{p}}$ ranges from $12 \%$ to $52 \%$ across all regions and species. In other words, for $\mathrm{RF}_{\mathrm{p}}$ contributed by almost any given region, the forcing imposed outside the region's territory due to atmospheric transport is stronger than the forcing imposed upon its territory. This is because a large fraction of aerosols are transported away from the region's territory (Supplementary Fig. 8), and BC exerts enhanced RF per unit of mass when transported to higher altitudes ${ }^{2}$. For any given region and species, the territorial percentage for $\mathrm{RF}_{\mathrm{c}}$ is always smaller than the percentage for $\mathrm{RF}_{\mathrm{p}}$. For Western Europe, the percentage for $\mathrm{RF}_{\mathrm{c}}$ is $14 \%$ for SIOA+POA and $12 \%$ for $\mathrm{BC}$, smaller than that for $\mathrm{RF}_{\mathrm{p}}$ ( $30 \%$ and $22 \%$, respectively) by a factor of two. For the Pacific OECD region, the percentage for $\mathrm{RF}_{\mathrm{c}}$ is $8 \%$ for SIOA+POA and $9 \%$ for $\mathrm{BC}$, smaller than that for $\mathrm{RF}_{\mathrm{p}}$ (20\% and $21 \%$, respectively) by a factor of 2.5 . These results suggest enhanced spatial spreading of consumption-associated aerosol RF via trade, in addition to the dispersion of emissions via atmospheric transport.

Our results show that a large portion of aerosol RF of East Asia is tied to consumption in the developed countries. This has an important effect on per capita RF. In particular, although aerosol 
a

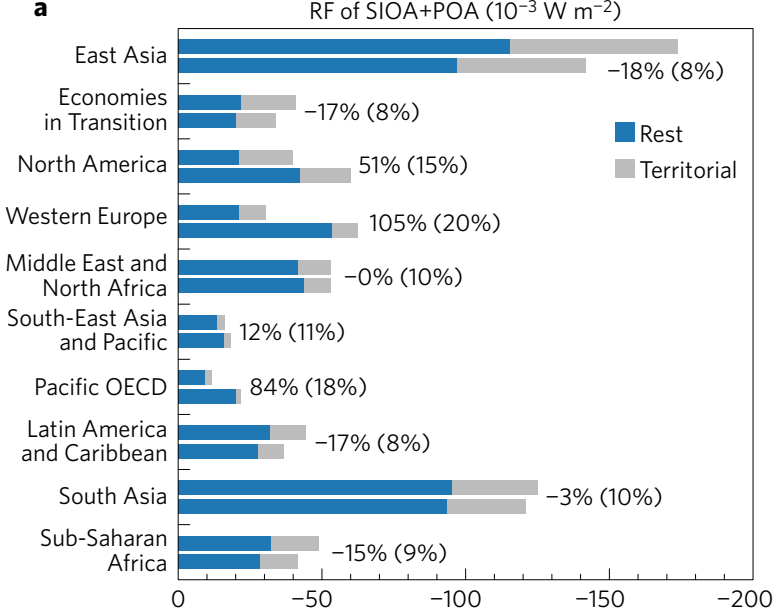

b

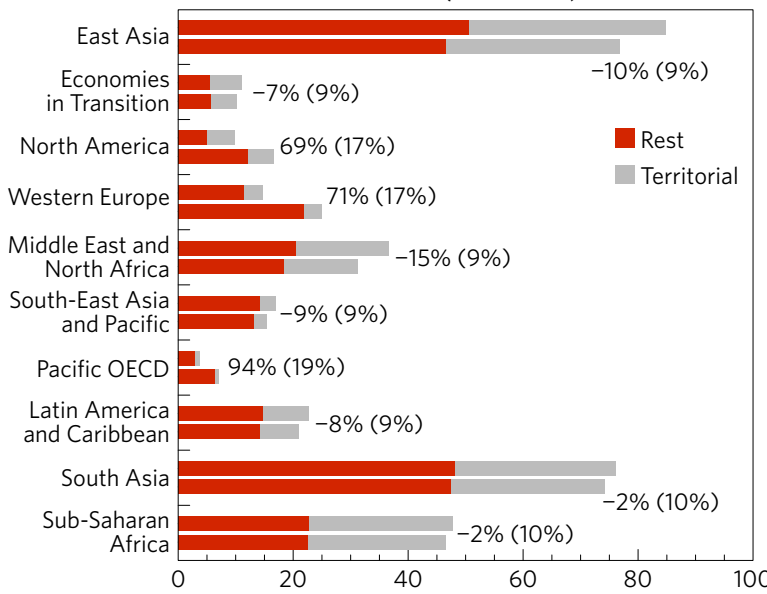

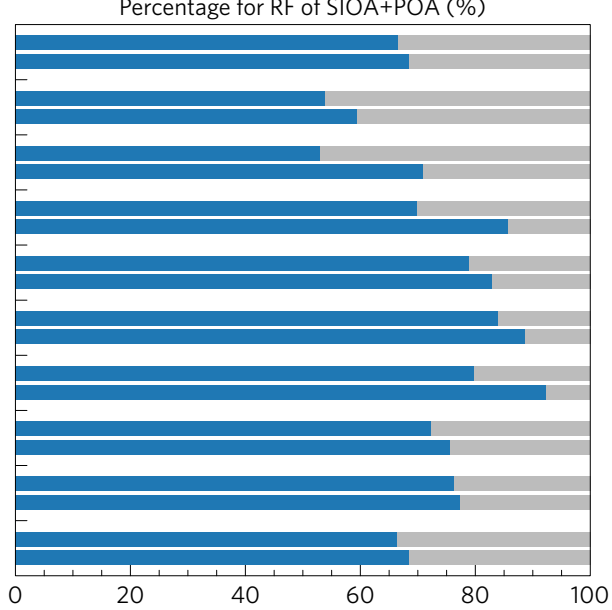

d

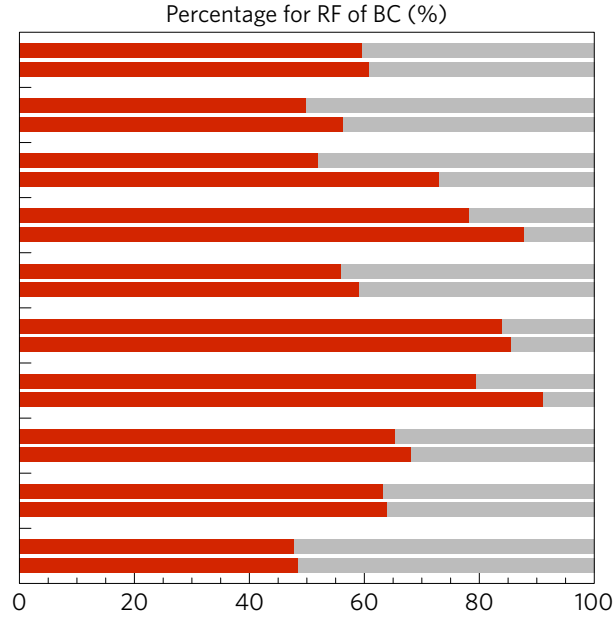

Figure $\mathbf{3}$ | Global production- and consumption-based radiative forcing of SIOA+POA and BC for all regions except Rest of the World. a,b, RF bar) and $\mathrm{RF}_{\mathrm{c}}$ (lower bar) contributed by individual regions, summed from the RF imposed above (grey) and outside (blue in $\mathbf{a}$ and red in $\mathbf{b}$ ) their territories. For a given region, the percentage value indicates the relative change from $\mathrm{RF}_{\mathrm{p}}$ to $\mathrm{RF}_{\mathrm{c}}$, and the value in the parenthesis is the associated error $(2 \sigma)$. $\mathbf{c}, \mathbf{d}$, Similar to $\mathbf{a}, \mathbf{b}$, but highlighting the percentages of RF imposed above (grey) and outside (blue in $\mathbf{c}$ and red in $\mathbf{d}$ ) the territory of a given region.

$\mathrm{RF}_{\mathrm{p}}$ per person in East Asia is larger than $\mathrm{RF}_{\mathrm{p}}$ per person in North America and Western Europe (by 6-94\% for SIOA+POA and 97-110\% for BC, respectively), the sign of difference can be reversed when evaluated on the basis of consumption (for example, $\mathrm{RF}_{\mathrm{c}}$ per capita of East Asia's SIOA+POA is weaker than North America by $43 \%$ and Western Europe by 23\%) (Supplementary Fig. 9).

\section{Trade-associated indirect RF and health impacts}

In addition to their direct RF quantified here, aerosols can affect cloud and precipitation processes and lead to indirect forcing on the regional and global climate ${ }^{1,8,12}$. This indirect effect, although much harder to quantify due to current limitations in the understanding and modelling of the hydrological cycle ${ }^{1}$, is also influenced by the proportion of a given region's consumption supplied via trade. Moreover, aerosols are harmful pollution to human health, causing more than three million premature deaths globally, including more than one million mortality in China, in $2010^{25}$. And trade is associated with a large quantity of deaths in regions supplying foreign consumption ${ }^{23,26}$. For example, aerosol pollution associated with China's export causes an estimated 157,000 Chinese deaths in $2007^{26}$, more than the deaths in the United States and the United Kingdom together from all ambient aerosol and ozone pollution in $2010^{25}$. Thus, trade plays a critical role in connecting global production and consumption and associated pollutant emissions, health impacts and climate forcing.

\section{Implications for global emission control}

The large aerosol direct RF contributed by East Asia and South Asia reflects these regions' fast growing economies, urbanization, coaldominated energy sources, and relatively inefficient energy technologies and emission controls ${ }^{13,27}$. Over the past decade, Chinathe largest emitter of aerosols and precursors in East Asia and the world-has made considerable progress in reducing its productionbased emissions $\left(E_{\mathrm{p}}\right)$-for example, $\mathrm{SO}_{2}$ emissions from coal-fired power plants were halved from 2005 to $2010^{28}$. Furthermore, China's $\mathrm{CO}_{2}$ emission mitigation plan (that is, Intended Nationally Determined Contribution ${ }^{29}$ ) will have substantial co-benefits for reducing aerosol emissions by improving energy efficiency and boosting contribution from renewable energy sources. India has made similar pledges $^{30}$. Together these efforts will help to offset the effects of economic growth and increasing consumption on RF and human health, but the effects of trade highlighted by our analysis may partially counteract this progress if the long-term trend of offshoring production from Western Europe and North America to Asia ${ }^{31}$ persists. Thus, trade, environmental, and public health policies may be improved by explicitly considering the substantial geographical transfer of aerosol emissions and impacts related to international trade $\mathrm{e}^{13,20,22}$. Despite stringent policies in the developed countries, global emissions of many aerosol pollutants have increased in recent years, implying that efforts may need to be extended to consider emissions embodied in trade ${ }^{20}$. To the extent these efforts seek to 
reduce the radiative forcing and health impacts of aerosols, mitigation of emissions in the developing countries promises to be far less expensive than the incremental improvements in the relatively much-cleaner energy systems of the most-developed regions. For example, extension and revision of funding and technology transfer programmes such as the Clean Development Mechanism developed under the Kyoto Protocol to include aerosol pollution might effectively reduce aerosol climate forcing and also help to improve air quality. Policymakers in the developing countries might also consider the extent to which the costs of more stringent environmental regulations could be passed along to consumers in other regions. Our findings thus suggest the possibility of analyses that compare the regional impacts of aerosols to the economic benefits of trade and the costs of improving production technologies. Such analyses may serve as a scientific basis for political instruments addressing the trade-related environmental issues.

\section{Methods}

Methods, including statements of data availability and any associated accession codes and references, are available in the online version of this paper.

Received 22 May 2016; accepted 22 July 2016; published online 5 September 2016

\section{References}

1. Myhre, G. et al. in Climate Change 2013: The Physical Science Basis (eds Stocker, T. F. et al.) Ch. 8 (IPCC, Cambridge Univ. Press, 2013).

2. Bond, T. C. et al. Bounding the role of black carbon in the climate system: a scientific assessment. J. Geophys. Res. 118, 5380-5552 (2013).

3. Hansen, J. et al. Efficacy of climate forcings. J. Geophys. Res. 110, D18104 (2005).

4. Jacobson, M. Z. Strong radiative heating due to the mixing state of black carbon in atmospheric aerosols. Nature 409, 695-697 (2001).

5. Ramanathan, V. \& Carmichael, G. Global and regional climate changes due to black carbon. Nat. Geosci. 1, 221-227 (2008).

6. Ruckstuhl, C. et al. Aerosol and cloud effects on solar brightening and the recent rapid warming. Geophys. Res. Lett. 35, L12708 (2008).

7. Shindell, D. \& Faluvegi, G. Climate response to regional radiative forcing during the twentieth century. Nat. Geosci. 2, 294-300 (2009).

8. Bollasina, M. A., Ming, Y. \& Ramaswamy, V. Anthropogenic aerosols and the weakening of the South Asian summer monsoon. Science 334, 502-505 (2011).

9. Leibensperger, E. et al. Climatic effects of 1950-2050 changes in US anthropogenic aerosols-Part 2: climate response. Atmos. Chem. Phys. 12, 3349-3362 (2012).

10. Wang, Y. et al. Assessing the effects of anthropogenic aerosols on Pacific storm track using a multiscale global climate model. Proc. Natl Acad. Sci. USA 111, 6894-6899 (2014).

11. Fiore, A. M. et al. Global air quality and climate. Chem. Soc. Rev. 41, 6663-6683 (2012).

12. Lau, K. M. \& Kim, K. M. Observational relationships between aerosol and Asian monsoon rainfall, and circulation. Geophys. Res. Lett. 33, L21810 (2006).

13. Lin, J.-T. et al. China's international trade and air pollution in the United States. Proc. Natl Acad. Sci. USA 111, 1736-1741 (2014).

14. Liu, Z. et al. Reduced carbon emission estimates from fossil fuel combustion and cement production in China. Nature 524, 335-338 (2015).

15. Moran, D. D., Lenzen, M., Kanemoto, K. \& Geschke, A. Does ecologically unequal exchange occur? Ecol. Econ. 89, 177-186 (2013).

16. Blanco, G. et al. in Climate Change 2014: Mitigation of Climate Change (eds Edenhofer, O. et al.) Ch. 5 (IPCC, Cambridge Univ. Press, 2014).
17. Guan, D. et al. The socioeconomic drivers of China's primary PM2. 5 emissions. Environ. Res. Lett. 9, 024010 (2014).

18. Peters, G. P., Minx, J. C., Weber, C. L. \& Edenhofer, O. Growth in emission transfers via international trade from 1990 to 2008. Proc. Natl Acad. Sci. USA 108, 8903-8908 (2011).

19. Weber, C. L. \& Matthews, H. S. Embodied environmental emissions in US international trade, 1997-2004. Environ. Sci. Technol. 41, 4875-4881 (2007).

20. Kanemoto, K., Moran, D., Lenzen, M. \& Geschke, A. International trade undermines national emission reduction targets: new evidence from air pollution. Glob. Environ. Change 24, 52-59 (2014).

21. Zhao, H. Y. et al. Assessment of China's virtual air pollution transport embodied in trade by using a consumption-based emission inventory. Atmos. Chem. Phys. 15, 5443-5456 (2015).

22. Oita, A. et al. Subtantial nitrogen pollution embodied in international trade. Nat. Geosci. 9, 111-115 (2016).

23. Takahashi, K. et al. Production-based emissions, consumption-based emissions and consumption-based health impacts of PM 2.5 carbonaceous aerosols in Asia. Atmos. Environ. 97, 406-415 (2014).

24. Narayanan, G. B., Aguiar, A. \& McDougall, R. Global Trade, Assistance, and Production: The GTAP 8 Data Base (Center for Global Trade Analysis, Purdue University, 2012).

25. Lim, S. S. et al. A comparative risk assessment of burden of disease and injury attributable to 67 risk factors and risk factor clusters in 21 regions, 1990-2010: a systematic analysis for the Global Burden of Disease Study 2010. Lancet 380, 2224-2260 (2012).

26. Jiang, X. et al. Revealing the hidden health costs embodied in Chinese exports. Environ. Sci. Technol. 49, 4381-4388 (2015).

27. Lu, Z., Zhang, Q. \& Streets, D. G. Sulfur dioxide and primary carbonaceous aerosol emissions in China and India, 1996-2010. Atmos. Chem. Phys. 11, 9839-9864 (2011).

28. Zhang, Q., He, K. B. \& Huo, H. Cleaning China's air. Nature 484, 161-162 (2012).

29. China Enhanced Actions On Climate Change: China's Intended Nationally Determined Contributions (Department of Climate Change, National Development \& Reform Commission of China, 2015).

30. India India's Intended Nationally Determined Contribution: Working Towards Climate Justice (Government of India, 2015).

31. Peters, G., Davis, S. \& Andrew, R. A synthesis of carbon in international trade. Biogeosciences 9, 3247-3276 (2012).

\section{Acknowledgements}

This research is supported by the National Natural Science Foundation of China (NSFC; 41422502 and 41222036), the 973 program (2014CB441303 and 2014CB441301), and World Wide Fund for Nature (WWF; 10010002399). Z.Lu and D.S. acknowledge the support of the Modeling, Analysis and Predictability (MAP) programme of the National Aeronautics and Space Administration (NASA) under Proposal No. 08-MAP-0143. Z.Liu acknowledges the support of NSFC (41501605). D.G. acknowledges the support of NSFC (41328008), the National Key R\&D Program of China (2016YFA0602604), the UK Economic and Social Research Council (ES/L016028/1), and the Natural Environment Research Council (NE/N00714X/1).

\section{Author contributions}

J.L., Q.Z. and Y.Huang conceived the research. D.T., D.P., H.Z., T.F., Z.L., D.S. and Q.Z. calculated the emissions. R.N., Y.Y. and J.L. conducted chemical transport model simulations. X.T., R.N., Y.Huang and J.L. conducted radiative transfer model simulations. J.L., S.D., Y.Huang and R.N. led the analysis and writing. All authors contributed to the writing.

\section{Additional information}

Supplementary information is available in the online version of the paper. Reprints and permissions information is available online at www.nature.com/reprints.

Correspondence and requests for materials should be addressed to J.L., Q.Z. or Y.Huang.

\section{Competing financial interests}

The authors declare no competing financial interests. 


\section{Methods}

Five steps are taken to derive $\mathrm{RF}_{\mathrm{p}}$ and $\mathrm{RF}_{\mathrm{c}}$ of aerosols. The first step develops an inventory of anthropogenic emissions of $\mathrm{SO}_{2}, \mathrm{NO}_{x}, \mathrm{CO}, \mathrm{BC}, \mathrm{POA}$ and $\mathrm{NH}_{3}$ produced in individual countries worldwide-that is, a country-based $E_{\mathrm{p}}$ inventory. The inventory is built because existing global inventories (for example, EDGAR and HTAP) do not specify for all species considered here the detailed sectoral information necessary for tracing emissions through the global supply chain. The second step derives the global emissions related to goods and services ultimately consumed by individual countries-that is, a country-based $E_{c}$ inventory-by tracing goods and services through the global supply chain. The third step projects the country-based $E_{\mathrm{p}}$ and $E_{\mathrm{c}}$ inventories on a longitude-latitude grid to facilitate the subsequent atmospheric modelling. The fourth step employs a chemical transport model (CTM) to calculate the atmospheric evolution and transport of emitted species and secondary products they form, including SIOA.

The gridded emissions are used to drive model simulations. The final step uses a radiative transfer model (RTM) to calculate the radiative forcing of aerosols, simulated by the CTM, related to production- or consumption-based emissions. The last two steps involve a series of CTM and RTM calculations to separate the $\mathrm{RF}$ of individual aerosols related to production or consumption of each of 11 aggregated regions. The 11 regions are chosen because of their geographic characteristics and economic and emission status (Supplementary Fig. 1). Detailed descriptions of these steps and related uncertainties are given in Supplementary Information.

Code availability. The code that supports the findings of this study is available from the corresponding authors upon request.

Data availability. The data that support the findings of this study are available from the corresponding authors upon request. The GTAP8 MRIOT is available at https://www.gtap.agecon.purdue.edu/databases/v8/default.asp. 